\title{
The Aesthetic Turn in Everyday Life in Korea
}

\author{
Kwang Myung Kim \\ Department of Philosophy, Soongsil University, Seoul, South Korea \\ Email: kmkim@ssu.ac.kr
}

Received May 30 $0^{\text {th }}$, 2013; revised June 30 ${ }^{\text {th }}$, 2013; accepted July $7^{\text {th }}$, 2013

\begin{abstract}
Copyright ( 2013 Kwang Myung Kim. This is an open access article distributed under the Creative Commons Attribution License, which permits unrestricted use, distribution, and reproduction in any medium, provided the original work is properly cited.
\end{abstract}

\begin{abstract}
We are living in the transitional age from the rational, analytical, and scientific to the cultural, sensitive, and aesthetic. The aesthetics of everyday life lies at the center of this age. There is no boundary between art and life in contemporary art. Almost all the contents and objects of everyday life became a work of art in the condition of searching for the aesthetic. Since aesthetic theory was shifted from the artist-centered or a work of art-centered to the audience, spectator or beholder-centered, art and everyday life were more closely related to each other. So aesthetic attention or attitude is not specific to art, but pervasive broadly in everyday life. We can embrace the aesthetic concerns in everything we make and use every day. In the long tradition of Korean art, it can be seen that aesthetic consciousness is steeped in day-to-day life as well as the arts. I want to consider the problems of everydayness, Korean aesthetic consciousness in daily life, and contemplation in the aesthetic consciousness. Korean art was characterized by its "lack of refinement" and "nonchalance". The characteristics of Korean art as the qualities of "technique without technique", "Planning without plan", "asymmetrical symmetry" have dominated the everyday consciousness of Korean people as well as Korean art. The extension of aesthetic emotion through experimentation shows us the change of aesthetic consciousness as a new possibility of interpretation. We stand in an urgent situation of the need for a new theory of art. It will be related to the future of aesthetics. For this reason, I think we have to consider the meaning of the aesthetic turn in everyday life.
\end{abstract}

Keywords: Aesthetics of Everyday Life; Everydayness; Aesthetic Turn; Korean Aesthetic Consciousness; Aesthetic Contemplation

\section{Introduction}

Why is the aesthetic turn in everyday life problematic? This century is often referred to as an age of culture and sensitivity. We are living in the transitional age of the aesthetic from the last ages of reason, analysis, and science. The aesthetics of everyday life lies at the center of this age. One of the important features of contemporary art is that there is no boundary between art and life. After demolishing the boundary between art and life, the aesthetics of everyday life have become particularly significant. Almost all of the contents and objects of everyday life became works of art in the condition of searching for the aesthetic. Since aesthetic theory was shifted from the artist-centered or a work of art-centered to the audience, spectator or beholder-centered, art and everyday life were more closely related to each other. So aesthetic attention or attitude is not specific to art, but pervasive broadly in everyday life. Not all, but most things in daily life can be literally works of art. Therefore, it does not need to distinguish between artistic creation or production and aesthetic judgment or evaluation. ${ }^{1} \mathrm{We}$ can embrace the aesthetic concerns in everything we make and use every day. In terms of the aesthetic experience as well as the aesthetic object, the aesthetic value that we can find in everyday life will be the main quest in the aesthetics of everyday life.

${ }^{1}$ Marcel Duchamp's readymade < Fountain > (1917), Andy Warhol's < Brillo Box> (1964), and John Cage's <4'33"> (1952) show us this well.
"Our current art- and spectator-centered aesthetics cannot adequately account for equally important aesthetic experience of everyday objects and activities, which almost always engage us bodily." ${ }^{2}$ For aesthetics to turn to everyday life, it needs to break down the boundaries between artist and beholder or spectator, art and ordinary things. Especially in daily life, the aesthetic and the practical cannot be neatly separated. On behalf of an aesthetic interpretation for meaning, everyday experience can be an object of aesthetic appreciation. The favorite symbols for beauty convey the transience of existence, such as falling cherry blossoms, misty mornings, rainy fields, snowy valleys and windy forests, etc. Fallen leaves in Autumn and other materials, like withered trees or a decayed old tree, especially signify the effects of aging accompanied by loneliness and melancholy. Many of our everyday objects and activities are undergoing change, therefore they can heighten our awareness and enhance the experience. ${ }^{3}$ In everyday life, which is dominated by time, we can find exquisite beauty. Transience and impermanence are apparent and are appreciated in the everyday life of aesthetic traditions.

"The aesthetics of everyday life is one of the distinctive contributions of philosophers to cultural studies, offering alternative to the emphasis on mass culture in the field. Instead of

\footnotetext{
${ }^{2}$ Yuriko Saito, “Everyday Aesthetics”, Philosophy and Literature, Vo. 25, No. 1, April, 2001, p. 89.

${ }^{3}$ Yuriko Saito, ibid., p. 91.
} 
film or television, everyday aesthetics shifts our attention to practices such as cleaning, homemaking, cooking, and wardrobe". 4 These everyday things can contribute to works of art as well as cultural indicators. ${ }^{5}$ Aesthetic character of everyday life permeates popular culture. As far as emotions are concerned, most everyday experiences may have more or less aesthetic value. Emotions in everyday life are directly expressed without practical or theoretical filtration. So, the expressions of raw images tell us original feelings hidden in our mental states. Aesthetic expression of day-to-day life is contributing to the enhancement of a better quality of life. It reminds us of the sensitivity hidden behind the reason, and thus it restores the wholeness of humanity. Now I want to consider the problems of everydayness, Korean aesthetic consciousness in daily life, and the contemplation in the aesthetic consciousness.

\section{Everydayness in Everyday Aesthetics}

The reason I deal with the meaning of the everydayness of life is to lead a good everyday life. Everydayness belongs to the everyday world. And it belongs to "the aesthetics of everyday domestic existence". 6 Looking to the dictionary meaning, everydayness is the quality or state of happening everyday or frequently. Sometimes it points to the product or result of things happening everyday or frequently, as well. Everydayness appears as appropriate for ordinary days, routine occasions or commonplace things such as housing, modes of dress, eating and drinking, gardening, packing, weather etc. "Each object (an armchair just as much as a piece of clothing, a kitchen utensil as much as a house) was thus linked to some 'style' and therefore, as a work, contained while masking the larger functions and structures which were integral parts of its form."7 The day-to-day supplies of each are important components that make up the structure, form, and in the end, style. Individual style transforms gradually into social style or country style, world style, and the style of the age. "The concept of everydayness does not therefore designate a system, but rather a denominator common to existing systems including judicial, contractual, pedagogical, fiscal, and police systems."8 Everydayness does not reveal the extraordinary in the ordinary, but rather it is the common ground in the ordinary systems. Everydayness consists of the important element of everyday artistic styles.

Everydayness or ordinariness in everyday life appears throughout popular culture. The ideas, perspectives, attitudes of popular culture permeate the everyday lives of the society. It shows aesthetic character of everyday life. Certain aspects of an experience appear as vague. However, if some of everyday experiences may have both unity and closure in the meaning of J. Dewey, then it cannot be mere experience, but an aesthetic experience with an aesthetic value. ${ }^{9}$ Of course aesthetic experiences are rooted in the pattern of everyday life. "Everydayness changes how we apply conceptions of aesthetic value. The best version of the aesthetics of everyday life upholds the Kan-

\footnotetext{
${ }^{4}$ Kevin Melchionne, “Aesthetic Experience in Everyday Life: A Reply to Dowling”, British Journal of Aesthetics, Vol. 51, No. 4, Oct. 2011, p. 437.

${ }^{5}$ Arthur C. Danto, what art is, New Haven: Yale University Press, 2013, p. 148.

${ }^{6}$ Arthur C. Danto, ibid.

${ }^{7}$ Henri Lefebvre, "The Everyday and Everydayness", trans. Christine Levich, Yale French Studies, No. 73, 1987, p. 8.

${ }^{8}$ Henri Lefebvre, ibid., p. 9

${ }^{9}$ J. Dewey, Art as Experience, New York: Perigee, 1934, pp. 35 \& 37.
}

tian distinction between mere agreeableness and genuine beauty, that is, between idiosyncratic or trivial sensations and judgments with normative force, that is, the sense of universal validity or sensus communis."10 Sensus communis (common sense) is one of the important concepts that dominate the everyday. It is a keyword of everydayness. It plays a significant role in Kantian aesthetics.

Aesthetics as a discipline of sensuous cognition is a science of sensuous representation and it contains unclear, confused awareness. On the contrary, logic is a science of clear and distinct representation. According to A. G. Baumgarten, "confused" means very uniquely, that is to say, not the scrambled sign of any situation, but the closely fused sign. In Kantian aesthetics, common sense reveals the confusedness of emotional perception or sensitive cognition. It will be able to broaden the horizons of cognition in relation to its unique epistemological status. Common sense is a ground for the intersubjective validity of the judgment of taste. ${ }^{11}$ Aesthetic judgment is based on the common understanding of common sense. In other words, common sense is the sense of community as the basis of aesthetic judgment. The sense of community that causes us to have communal meaning is to share feelings with each other.

The pleasure we get by making a judgment about the sensuous object in general has a universal postulate as a subjective purposiveness of the representation on the relationship between two cognitive faculties, namely, reason and understanding. In particular, the beauty is neither an object of the concept, nor cognitive judgment. Its deduction is not clarified by objective reality. It is just subjective and formal. Common sense can make it possible to bring the communication. If sensation as the reality of perception is related to the cognition, then we call it sensory perception. ${ }^{12}$ When we perceive things through our sense organs, we can feel pleasure. This pleasure is not attributable to spontaneity, but to receptivity. Taste as a sort of common sense can be shared with each other. We accept it as an idea that is attributed to the common sense. ${ }^{13}$ This is similar to the common idea that is shared by a community. Usually a maxim of the human understanding that we call common sense helps to explain the principles of the judgment of taste. The non arbitrary and unprejudiced maxim of thoughts is the maxim of an active reason. However, aesthetic taste is to be called common sense rather than to be referred to as a sound understanding. Though common sense is the subjective judgment of taste, despite the subjective condition, it is universally communicable.

Aesthetic life in everyday is marked by pervasiveness and routine to everybody. Aesthetic character is permeated into everyday life. Like common sense, when joining in a common experience we can share an aesthetic sense with others in everyday life. Many of our daily experiences in the pleasure of beauty give us reflective pleasure sharable with each other. "Our everyday experiences are entrenched in practical, functional, everyday activities and concerns. Everyday objects and activities are created, used, or performed primarily for non aesthetic purposes." 14 There is simply more of everyday aes-

\footnotetext{
${ }^{10}$ Kevin Melchionne, ibid., p. 438.

${ }^{11}$ John H. Zammito, The Genesis of KANT's Critique of Judgment, The University of Chicago Press, 1992, p. 2.

Taste is distinct from appetite and matters only in society (cf., p. 31).

${ }^{12}$ I. Kant, Kritik der Urteilkraft, Hamburg:Felix Meiner, 1974, § 39, 153.

${ }^{13}$ I.Kant, ibid., § 40, 157.

${ }^{14}$ Christopher Dowling, "The Aesthetics of Daily Life”, British Journal of Aesthetics, Vol. 50, No. 3, July 2010, p. 232.
} 
thetic life than there is of museum visits or nights at the theatre. "Everydayness substantially changes how we value our experiences. It changes how we observe and describe. To recognize aesthetic value in everyday life, one has to look at more than just the tiniest slivers of experience" ${ }^{15}$ So we come to interpret the meaning of skill or technique, function and excellence in everyday life. These three concepts distinguish and identify the limits between everyday life and art.

In making an everyday living it has long been noticed that fashions in dress, and fashion in decoration, style in architectture have a similar tendency to imitate and promote each other. These tendencies reflect the changing ways in which the human being and the human body are perceived. ${ }^{16}$ As the aesthetic denotes the sensuous aspect of our appreciation of beauty, bodily perception is contained in the aesthetic consciousness. I see body as a subject of perception and communication. If we define the aesthetics as a cognitive science of world by bodily perception, it is loyal to the original definition of discipline, "aesthetics". Body, the physical structure, including the bones, flesh, and organs, of a person or an animal is the primary exit for perceiving world. ${ }^{17}$ We feel or experience the grace through a graceful (slender) figure as an important aspect of body everyday. In figure, gesture and gesticulation we can read the fusion of inner and outer world. And is the same case in action and motion.

Through the activities of the emotional experience in the field of human life we can recognize and meet the world. Especially in the area of culture and art, we can feel it with the skin. Everyday aesthetics concerns itself with the mental states, worldviews and artifacts that are immersed in daily life. It takes an aesthetic character from the stream of cultural, environmental elements. "A faculty that is directed towards natural beauty would have a real chance of being both a human universal, and founded in some universal claim, in other words, a claim of reason."18 Strictly speaking, aesthetic reasoning is an analogy of reason rather than a claim of reason. It is not an interest in the way things present themselves, but a disinterested interest in appearances. This disinterestedness will be considered in relation to contemplation. Disinterestedness revolves to the interest itself beyond the interest. Interest itself meets with the state of contemplation.

"An experience can have meaning for us in one of two ways: the way of perception and the way of imagination. The way of perception involves the use of our sensory capacities to gain information about the world, and this information comes to us in two forms: as part of the way things appear to us, and as an inference from the way things appear." 19 Though perception is made on the basis of reality, the imagination, beyond the constraints of time and space, extends our reality in everyday life. "The way of imagination is illustrated. My visual experience contains a kind of narrative. This narrative is presented through the appearance of the picture. ${ }^{20}$ Narrative in the everyday pre-

\footnotetext{
${ }^{15}$ Kevin Melchionne, ibid., p. 440.

${ }^{16}$ Roger Scruton, "In Search of the Aesthetic”, British Journal of Aesthetics, Vol. 47, No. 3, Jan. 2007, p. 244.

${ }^{17}$ Recently we have seen a considerable resurgence in the popularity of tattooing and piercing, a development that some have dismissed as a fashionable trend, others have argued that the relative permanence of such forms of body modification militates against their full absorption into the fashion system.

${ }^{18}$ Roger Scruton, ibid., pp. 238-239.

${ }^{19}$ Roger Scruton, ibid., p. 246.

${ }^{20}$ Roger Scruton, ibid., p. 247.
}

sents connection of events and describes a sequence of events in various categories like fiction and non-fiction including all creative products of human beings. Aesthetic everyday stands on the basis of day-to-day experience, but sometimes "beyond" the day-to-day. Under the name of "beyond" it can awake the extraordinary in the ordinary life. ${ }^{21}$ We can approach and perceive our daily lives and imagine the extraordinary in the ordinary. The ordinary can be transformed and transfigured into the extraordinary. We encounter the extraordinary in daily life. ${ }^{22}$ Linkage that connects the two sides is the aesthetic consciousness.

\section{Korean Aesthetic Consciousness and Everyday Life}

I would like to consider aesthetic emotion and aesthetic expression in everyday life of Korean people. It is naturally related to the Korean cultural tradition. Though influenced by other Asian cultures, its roots lie deep in the creative Korean psyche. Especially despite the impact of Chinese culture, however, Korean art has always managed to maintain a uniquely Korean quality, namely a tranquil and relaxed attitude, quite distinct from the elaborate and massive forms of China or the highly delicate style of Japanese art. ${ }^{23}$ The delicate styling and fine craftsmanship of celadon pottery illustrates the refinement of the culture well. We can feel stylish aesthetics of Korean food, clothing, and shelter life, etc. Sympathetic voice, a tone of color, fragrance, stylish story, and sense of beauty that can be found in everyday life show us the aesthetic sense of the Korean people. Aesthetic emotion can be felt in the extremely ordinary. Tiled roofs of a Korean-style house, splashed lift the eaves line, a wooden crosspiece of grid in the traditional house, curved cabrioles used in a small dining table with cabrioles are indigenous to the Korean life style. Aesthetic taste is shown in food, such as garnish put on a feast noodles or rice cake soup, sliced yellow decorative seasonings, shredded red pepper with white noodles, or rice cake on top of soup, the visual stimuli are a great way to stimulate the palate. Adorning the sincerity of food, as well as the pleasant taste improves dignity. And taste is shown in traditional Korean costume or clothes. We can feel an aesthetic sense in refinement from a narrow path or a trail. These would bring the room to life and cause us to contemplate life.

In a Korean literary man's life, we find not separate, but in one form of poetry, calligraphy, painting and carving. For a man of letters, refined tastes and poetic elegance grew out of time and space to spare. A wind-bell is hanging from the eaves in a Buddhist temple, its sound immerses us in the natural world. We can experience eternity in the moment. It says that everyday will lead to an eternity. Transience and permanence are not two, but one. Everyday aesthetics is immersed in the natural world as an aesthetic contemplation. In Korea as well as in the world, one of the main characteristics of contemporary arts is diversity. Contemporary arts display diverse and multifaceted views. In contemporary art, individual sensibilities and idiosyncrasies manifest themselves without restriction, and

\footnotetext{
${ }^{21} \mathrm{cf}$. Eric Booth, The Everyday Work of Art: Awakening the Extraordinary in your Daily Life, Lincoln, NE: iUniverse, 2001.

${ }^{22}$ Thomas Leddy stresses aesthetic Aura in everyday experiences. cf. The Extraordinary in the Ordinary: The Aesthetics of Everyday, Broadview Press, 2012.

${ }^{23}$ Kwang Myung Kim, "Korean Aesthetic Consciousness and the Problem of Aesthetic Rationality”, Canadian Aesthetics Journal, Vol. 2, 1998.
} 
there are no specific ideas or rules to define them. Experimentalism and avant-gardism are considered as new challenges, inspirations, and possibilities away from a relatively conservative and dogmatic perspective of previous arts. They are also conventional but sensitive issues linked to the matters of tradition and modernity, of particularity and universality. "Contemporary art that challenges conventional artwork framework is those objects and performances that simulate or are situated in our everyday installation, performance, interactive piece, assemblage art." ${ }^{24}$ A symbol of special sentiment and sensibility expressed by the word, "Korean". The exquisite harmony and naturalness constituted by pieces with the aesthetic consciousness in Korean art. In addition, special aesthetic traits shaped unique sensitivity. Figures are made not by rules or principles, but by spontaneity, and by choices and acts in a moment of everyday.

"Folksong”, "popular ballad”, "folk arts" and "arts of the people" are related to everyday aesthetics. People keep and cherish them in heart. These come into being spontaneously. These grow and appear spontaneously. Korean folk crafts are handcrafted art of ordinary people in daily life. Their beauty can be discovered in everyday ordinary and utilitarian objects such as ceramics, lacquer, textiles, and woodwork, etc. created by nameless and unknown craftsmen. Crafts made by anonymous people produced by hand in quantity that are inexpensive. They are used by the masses and functional in daily life representative of the regions in which they were produced. Korean pottery which is produced with pure white clay has the beauty of daily life. Korean white pottery is marked by fine paintings in cobalt blue or iron red of natural images celebrating perfect balance, elegant form, subtle tranquility and simple beauty with high practicality in everyday. It is continued through transmission from the past to the present. In the context of the effective history of H.-G. Gadamer's hermeneutics, "the true historical object is not an object at all, but the unity of the one and the other, a relationship in which exists both the reality of history and the reality of historical understanding.,25

We can see characteristics of Korean beauty appearing in daily life. What is worth noting here is the essence of aesthetic consciousness. In folk painting we can read an aesthetics of simplicity and naturalness. It is often focused on the gods and spirits of the popular shaman. Shamanism is the most authentic cultural legacy of Koreans, but we have forgotten it in the course of acculturation, especially so-called westernization, modernization, or globalization. In Korean shamanism, the concept of the boundary between the outside world and the village itself is much stronger than the world-centered outlook. The symbol of wholeness found in Korean shamanism is expressed through the motif of harmony or the union of opposites, a reflection of the relationship between Yin and Yang as the cosmic dual forces. Yin and Yang are not the two antagonistic elements, but the coexistent elements. Buddhism, Confucianism, Taoism, and other religious elements influence the unique nature of the Korean character together with shamanism. In fact, they play a decisive role in determining the Korean mentality or consciousness. $^{26}$

For Koreans, nature is a mirror of the self and a world of meditation which gives life, restoring all things to their proper

\footnotetext{
${ }^{24}$ Yuriko Saito, Everyday Aesthetics, Oxford University Press, 2007, p. 32.

${ }^{25}$ Hans-Georg Gadamer, Truth and Method, trans. by Garret Barden and John Cumming, New York: the Crossroad, 1982, p. 267.

${ }^{26}$ Kwang Myung Kim, ibid.
}

state. Naturalism is an attribute of Korean art because of Koreans' indigenous view of nature, i.e. the view of holding communion with nature. However, the relativity in this concept of naturalism gives way to errors in the interpretation of the characteristics of Korean art. A distinguishing characteristic of Korean art is not naturalist in the western sense of the term. If the tradition of Korean art is set against the background of a "return to nature”, I think a more appropriate term is "pan-naturalism", because the nature portrayed in Korean art is not a product of an objective world, but an expression of an omnipresent view of nature bespeaking both the consciousness of human beings and the source of life. This pan-naturalism as naturalness, working in concert with post-naturalism, makes it possible to call a work of art genuinely Korean. ${ }^{27}$

Ko Yu-seup, the renowned art historian and aesthetician, once said Korean art was characterized by its "lack of refinement" and "nonchalance". In addition, he defines the characteristics of Korean art as the qualities of "technique without technique”, "Planning without planning”, "asymmetry”. It is not too much to say that these features have dominated everyday consciousness of the Korean people as well as Korean art. Here we can see also Kantian purposiveness without purpose, lawfulness without law, or conception without concept. "In most cases, a work of Korean art is probably not meticulous in minute details. It rather tends to embrace a wholeness, hence its savory taste in total effect. This nonchalance lies in the docile state of mind of Korean artists and artisans who love nature as it is." ${ }^{28}$ In Korean art we can confirm the compatibility of symmetry and asymmetry, technique and non-technique. Ko concluded that its lack of meticulous detail enabled it to be embraced by a wholeness larger than art and hence emanate a warm, comforting ambience.

Ko's view is a simple but eloquent description of the characteristics of traditional Korean art. However, it seems to be inadequate for clarifying the characteristics of contemporary Korean art. This is the reason why art is influenced continuously by trends and cultural changes. Nevertheless, I think his view represents the daily aesthetic consciousness of the Korean people. Today's art, for example, is conditioned to existent social, cultural, historical and religious contexts. It is very difficult to comprehend a work without understanding the culture of which played an important role in shaping the personality and mental attitude of the artist who created it. Korean aesthetics must be inherent in contemporary Korean art, regardless of its dominant Western influence. ${ }^{29}$ But we can here compare and pay attention to the problem of disinterestedness or non-technique applicable to everyday life as well as to art.

During the Japanese occupation in Korea (1910-1945), Japanese aesthetician Yanagi Muneyoshi defined Korean beauty as "beauty of sadness" and "innate, original beauty created by the Korean race” in his book Korea and its Art (1922). He was severely criticized by Korean intellectuals as presenting a "colonialist view of history". Yanagi believed that the long history of foreign invasions of Korea was reflected in Korean art, and especially in its pottery, in the "sad and lonely" lines. Such a theory has been criticized by Korean scholars as the "aesthetic of colonialism”. Another Japanese specialist in Korean Pottery, Tanaka Toyotaro, states that Korean ware is rather born than

\footnotetext{
${ }^{27}$ Kwang Myung Kim, ibid.

${ }^{28}$ Yu-Seup Ko, "Characteristic of Korean Art”, in his Essays on History of Korean Art and Aesthetics, Seoul: Tongmungwan, 1963, pp. 6-8.

${ }^{29}$ Kwang Myung Kim, ibid.
} 
made. His statement seems to emphasize naturalness and to exclude artificiality. "There is no linking of hesitation on the part of the potter", ${ }^{30}$ he adds. He also refers this point of view to spontaneity as an outstanding trait of Korean art. Evelyn McCune, an American art historian born in Korea, asserts that refinement and crudeness are the two polarizing qualities existing in Korean art. Both qualities reveal honesty and contribute to strength, or vitality. ${ }^{31}$ Here honesty is purity, a trust in nature. According to R. Griffing, Korean art is solid, straight-forward and modest and there is no sign of the classicism of Chinese intellects nor the technicality of the Japanese. ${ }^{32}$ I think this ambivalence of refinement and crudeness, asymmetry and symmetry, technique and non-technique is still valid in everyday aesthetic consciousness of Korean people as well as in Korean art.

D. Seckel defines "Koreanness", so to speak, typical characteristics of Korean art by detecting as follows: 1) The decomposition of form complexes into small elements like a mosaic work; 2) Flat in volume and graphically linear in surface design. Nevertheless, the underlying characteristics of Korean art are vitality, spontaneity and unconcern for technical perfection, i.e., nonchalance. ${ }^{33}$ These interpretations can actually be summed up in his terms like vitality, spontaneity and unconcern for technical perfection. Vitality is a strength, resulting from the nonchalance of a creator who is free from hesitation, and free from the conflict between the beautiful and the ugly. The strength is even enhanced as he reduces decorations and makes the best of the virtue of his materials itself, the texture and natural grain, for example, in the case of wood. This tendency is closely related, in the end, to the second and third virtues that we have often discussed, i.e. spontaneity and unconcern for technical perfection. Spontaneity is dual in nature. It involves an artist's attitude toward his work as well as his taste for a spontaneous quality. This love of spontaneity, for instance, is reflected in the tendency of leaving pottery an undecorated object, eliciting a delightful feeling of expanded space leading to the lack of artificial pretense. Thus, the nature of Korean art is often apparent in the everyday life of the Korean people.

\section{Aesthetic Contemplation in Everyday Life}

We are involved in day-to-day lives, and participants in everyday life. It appears to be routine. But contemplation keeps distance in everyday life and through reflexive process can reach the core of everyday life. What does it mean and why do we need to do? I think the purpose of contemplation is to find nature from the inside of the human. We are living in natural environments like seasonal changes of climate everyday. Sometimes we have a calm aesthetic contemplation of it. Our aesthetic tendencies and emotions are often affected by weather. For an instance, Japanese haiku as a very short form of poetry shows us the seasonal reference of the natural world. Saito says, "weather has been, is and will be, experienced by every human beings". ${ }^{34}$ Daily weather is constantly changing and affects us through many senses. In weather conditions we can feel aes-

\footnotetext{
${ }^{30}$ Tanaka Toyotaro, Yi Dynasty Ceramics, Tokyo, 1944, pp. 257-258.

${ }^{31}$ Evelyn McCune, The Arts of Korea, Turtle Co., 1962, p. 20.

${ }^{32}$ Asia House Gallery, "The Art of the Korean Potter", The Asia Society, 1968, p. 13.

${ }^{33}$ D. Seckel, "Some Characteristic of Korean Art”, Oriental Art, Spring 1997, pp. 52-61.

${ }^{34}$ Yuriko Saito, “The Aesthetics of Weather", in Andrew Light and Jonathan M. Smith (ed.), The Aesthetics of Everyday Life, Columbia Univ. Press 2005, p. 157.
}

thetic appreciation of transience and permanence at the same time. Saito directs her attention to subtle changes in the weather and the sense of the season that brings influences on our aesthetic emotions. The changes in the natural environment that has a deep association with our daily lives have a significant impact on our aesthetic emotions. The natural beauty in everyday life makes us have a space of time to immerse ourselves in aesthetic contemplation.

Korean art also tends to be devoid of an artificial movement and this reflects dislike of disturbance, deformation and convention. Thus, it guides us to a world of quiet contemplation. Korean art has been characterized by submission to nature, and the lack of the artificial consciousness. Thus it has developed within the framework of naturalism. Because of its multiplicity, naturalism as such is a vague term. To make it more precise, we must consider the Korean's basic philosophy lies not in a man-oriented idealism but in a naturalism oriented by nature. Its special historical background seems to have played a great part in the formation of their national character, such as acceptance of reality, resignation, optimism, trust in nature, escapism, and dislike of artificiality. But this reasoning looks insufficient to support our discussions on the character of Korean people and their art. A more satisfying answer for this can be found in a careful, synthetic consideration of various elements, such as topography, geography, history, cultural environment, and life, style, which constitute a specific composite whole. The cultural tradition of a people derives from a composite mode of life formed over a long period in a specific pattern of environment. Characteristics of a cultural tradition contribute in turn to the formation of a cultural tradition. ${ }^{35}$

The distancing with the objects is a sort of distinctive aesthetic attitude of Korean people. It is not participatory involvement, but contemplative distancing. Such an aesthetic attitude is not irrelevant to the long history that has dominated the daily life of Koreans. "Aesthetics concerns itself with states of mind, worldviews and artifacts that are immersed in, and take their character from the stream of human history., ${ }^{36}$ Everyday we interact with sensuous qualities like size, shape, color, texture, sound, sometimes smell. The Kantian term of "aesthetic" denoted the sensuous aspect of our appreciation of beauty. We appreciate and evaluate the arrangement of parts on a daily basis that make up the world in which we live. There are many aesthetic issues involved in our dealings with everyday things if these are closely related to sensuous aspects.

As noted a little above, in Kant's aesthetics, “disinterestedness” in the judgment of taste has a very unique meaning. People often consider disinterestedness as a lack of interest, and think it very negatively. Kantian disinterestedness is the concentration or harmony of interests. It excludes only the theoretical and practical concepts of interest, it just tends to the aesthetic interest. In other words, disinterestedness is similar to "interestedness without interest" like "purposiveness without purpose". Disinterestedness of pleasure in beauty is a sort of contemplative pleasure. ${ }^{37}$ According to Kant, disinterested contemplation is the capacity to see things in nature as intrinsically valuable, and as ends in themselves. Aesthetic disinterestedness

\footnotetext{
${ }^{35}$ Kwang Myung Kim, ibid.

${ }^{36}$ Roger Scruton, "In Search of the Aesthetic", British Journal of Aesthetics, Vol. 47, No. 3, Jan. 2007, p. 235.

${ }^{37} \mathrm{cf}$. Kwang Myung Kim, "Kant's Disinterestedness and the Characteristics of Korean Beauty”, in Kwang Myung Kim, Thinking on Art, Seoul: Hakyunmunhwa-sa, 2006.
} 
is only free from practical or theoretical interest. It is the focusing of attention itself and the harmony of interests for a full perceiving of the beauty. I think this disinterestedness can be compared with Buddhistic mind collected in one state. Buddhistic mind as a mindlessness is the opposite of the mindfulness. Mindfulness is the product of agony filled with desire, on the other hand, the mindlessness as an emptiness of the mind is the mental state of calmness and contemplation beyond any worldly desires.

Now in Buddha I want to explore the state of contemplation. In Buddhistic figural sculpture, the body, arms and particularly the face, are full and gracefully modeled, and unbroken lines run from the head to the tip of the toes. The drapery folds are depicted in animated realism, and the sensitive, human approach is immaculately perfected by technical excellence with an overall effect and pattern, definitely Korean. This idealistic naturalism has been the basic undercurrent in Korean art throughout the ages. We can observe the dual meaning of symmetry and asymmetry, technique and non-technique. Despite the dual meaning, the culmination of Silla ${ }^{38}$ sculpture is shown well in its technical symmetry and witnessed by the sculptures of the Sokkuram cave-temple that date from the mid-8th century. The main Buddha within the stone-built circular domed structure is a colossal seated Buddha surrounded by relief-figures of Disciples. The main Buddha, carved out of a single block of granite, is an imposing monument. It is, however, not awkward or stiff, and there is a feeling of warmth beneath the cold stone surface. The facial expression is a perfect combination of the spiritual Buddha and the historic man, creating an eternal peace and calmness. In every figure within the artificial cave, traditional Korean naturalism and a slight touch of conventionalism are combined to create a sensitive yet divinely spiritual religious statue. ${ }^{39}$ The figure of Buddha is very similar to the figure of everyday Korean people at that time.

Immersion in the natural world is well appeared in Korean people as well as in Korean art. Especially pan-naturalism or naturalness is related to the Korean mentality and aesthetic consciousness. Mindfulness and mindlessness are not contrary. Mindful contemplation is the state of mindlessness. Aesthetic approach to the object itself makes it possible to get the state of mindlessness, namely contemplation.

\section{Conclusion}

So called, in the end era of art or after the end of art, according to Danto, "it became apparent that there were no stylistic or philosophical constraints. There is no special way works of art have to be. And that is the present and, I should say, the final moment in the master narrative. It is the end of the story". ${ }^{40}$ Anyway there is no more a boundary between art and non-art, even anti-art. We are living in the time when everything coexists in entanglement. The aesthetics of the present is the aesthetics of the everyday. "Much of contemporary art is hardly aesthetic at all, but it has in its stead the power of meaning and the possibility of truth, and depends upon the interpretation that

\footnotetext{
${ }^{38}$ In the Unified Kingdom of Silla (668-935) period, this was the golden age of ancient Korean art, especially Buddhist statues, granite Buddhist images and pagodas.

${ }^{39}$ Kwang Myung Kim, "Korean Aesthetic Consciousness and the Problem of Aesthetic Rationality”, Canadian Aesthetics Journal, Vol. 2, 1998.

${ }^{40}$ Arthur C. Danto, After the end of art: contemporary art and the pale of history. Princeton Univ. Press, 1998, p. 47.
}

brings these into play." ${ }^{41}$ The aesthetic is not closed, but open to everything, everybody and everyday.

If we are to consider Korean contemporary art from the global perspective, we must define what it means to be Korean, i.e. our cultural habits and artistic elements hidden behind the Korean aesthetic consciousness. It's the problem of the identity as well. In this era of globalization, the question of Korea's artistic identity is attracting a lot of attention. While many point to the relevance of national identity, the question of the individual artist's personal identity also seems important. Korean artists must concern themselves with specific issues. Namely, they have to take a broad view toward the idea of visual media. And they have to transcend the narrow sensory, conceptual, and formal significance of arts to discover its fundamental character. They must constantly review their own society, and their own culture, for ultimately their art is rooted in their own national cultural sensibility. It's much more than a question of how we portray our Korean aesthetic consciousness.

Korean contemporary art shows us a clear tendency toward stylistic pluralism and creative individualism. While experimentation in the new media is encouraging, experimentalism should be a means of reacting to the mainstream, not a means of destroying it. In our contemporary world, the human consciousness is no longer dominated by a single idea or ideology. Everyday we attempt to look at all aspects of life from an individual point of view, and it is a valuable achievement in this age of fluidity and openness. Beneath the individual lives and everyday experiences lie more layers of truth to be revealed and redefined in the future.

As in the case of western avant-garde, experimentation makes our reality reflective. Experimental methods make the art world free from the restrictions of tradition. Each method strove to break with traditional limitations, although there were many variations and degrees of experimentation. It is only the relic of the past to reject the stream of change. Something new comes off not from the separation between the past and the present, but from the historical continuity in the name of effective history. In this age of multiculturalism, the new interpretation of tradition makes it possible to merge Korean art with the global stage. The extension of aesthetic emotion through experimentation shows us the change of aesthetic consciousness as a new possibility of interpretation. We are in urgent need of a new theory of art. It will be related to the future of aesthetics. Every day as a moment is connected to the future. It is not only a present, but also a represent. ${ }^{42}$

\section{REFERENCES}

Asia House Gallery (1968). The art of the Korean potter. The Asia Society.

Booth, E. (2001). The everyday work of art: Awakening the extraordinary in your daily life. Lincoln, NE: iUniverse.

Danto, A. C. (1998). After the end of art: Contemporary art and the pale of history. Princeton: Princeton University Press.

Danto, A. C. (2013). What art is. New Haven: Yale University Press.

Dewey, J. (1934). Art as experience. New York: Perigee.

Dowling, C. (2010). The aesthetics of daily life. British Journal of Aesthetics, 50. doi:10.1093/aesthj/ayq021

Gadamer, H.-G. (1982). Truth and method. New York: The Crossroad. Kant, I. (1974) Kritik der urteilkraft. Hamburg: Felix Meiner.

\footnotetext{
${ }^{41}$ Arthur C. Danto, what art is, Yale University Press, 2013, p. 155.

${ }^{42} \mathrm{I}$ am grateful to Prof. Mitch Green and Mr. Cliff Maxwell at the University of Virginia for his helpful comments and improvements on my paper.
} 


\section{K. M. KIM}

Kim, K. M. (1998). Korean aesthetic consciousness and the problem of aesthetic rationality. Canadian Aesthetics Journal, 2.

Ko, Y.-S. (1963). Characteristic of Korean art. In Essays on History of Korean Art and Aesthetics. Seoul: Tongmungwan.

Leddy, T. (2012). The extraordinary in the ordinary: The aesthetics of everyday. Broadview Press.

Lefebvre, H. (1987). The everyday and everydayness. Yale French Studies, 73.

McCune, E. (1962). The arts of Korea. Turtle Co.

Melchionne, K. (2011). Aesthetic experience in everyday life: A reply to dowling. British Journal of Aesthetics, 51.

Saito, Y. (2001). Everyday aesthetics. Philosophy and Literature, 25. doi:10.1353/phl.2001.0018

Saito, Y. (2005). The aesthetics of weather. In A. Light, \& J. M. Smith (Ed.), The aesthetics of everyday life, New York: Columbia University Press.

Saito, Y. (2007). Everyday aesthetics. Oxford: Oxford University Press Scruton, R. (2007). In search of the aesthetic. British Journal of Aesthetics, 47. doi:10.1093/aesthj/aym004

Seckel, D. (1997). Some characteristic of Korean art. Oriental Art.

Toyotaro, T. (1944). Yi dynasty ceramics. Tokyo.

Zammito, J. H. (1992). The genesis of KANT's critique of judgment. Chicago: The University of Chicago Press. 